\title{
La cultura andina en la globalización: Hacia un diseño de la integración
}

\author{
Mihaela Radulescu de Barrio de Mendoza
}

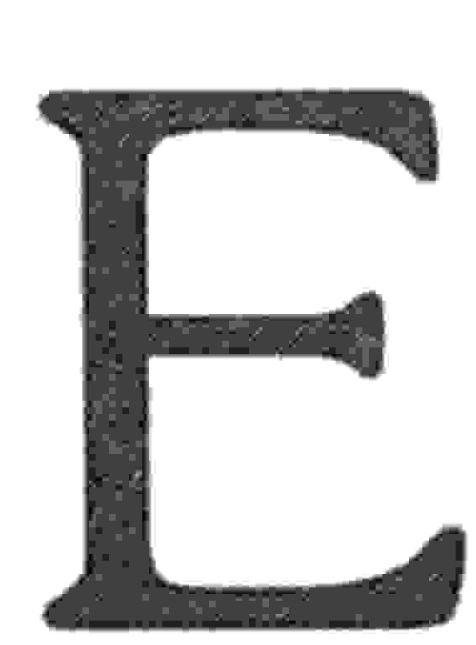

1 diseño de formas y objetos, desarrollado tradicionalmente por la cultura andina como práctica participativa, que propone la inclusión en vez de la exclusión, encontró un campo privilegiado en la globalización.

En sus inicios, propuso el acercamiento de la cultura a la naturaleza, a través del uso de las prácticas analógicas. Por circunstancias históricas, la analogía se volvió interculturalidad, con distintos niveles de hibridación de la imagen, hasta llegar al sincretismo.
Hoy en día, con la globalización emergente, la hibridación ingresa en una compleja red de interacciones $y$, en vez del intercambio de valores entre dos culturas, nos encontramos frente a un espacio dinámico recorrido por acciones comunicativas que unen diversas culturas en un posible sistema de intercambios. La pregunta es: ¿Cómo intervenir en este espacio para que los intercambios simbólicos funcionen?

El interés de cada comunidad es, no sólo recibir y dar en el concierto global de las culturas, sino - en su propio espacio - equilibrar las 
interacciones y organizarlas en torno a su propia identidad, como centro de su cultura.

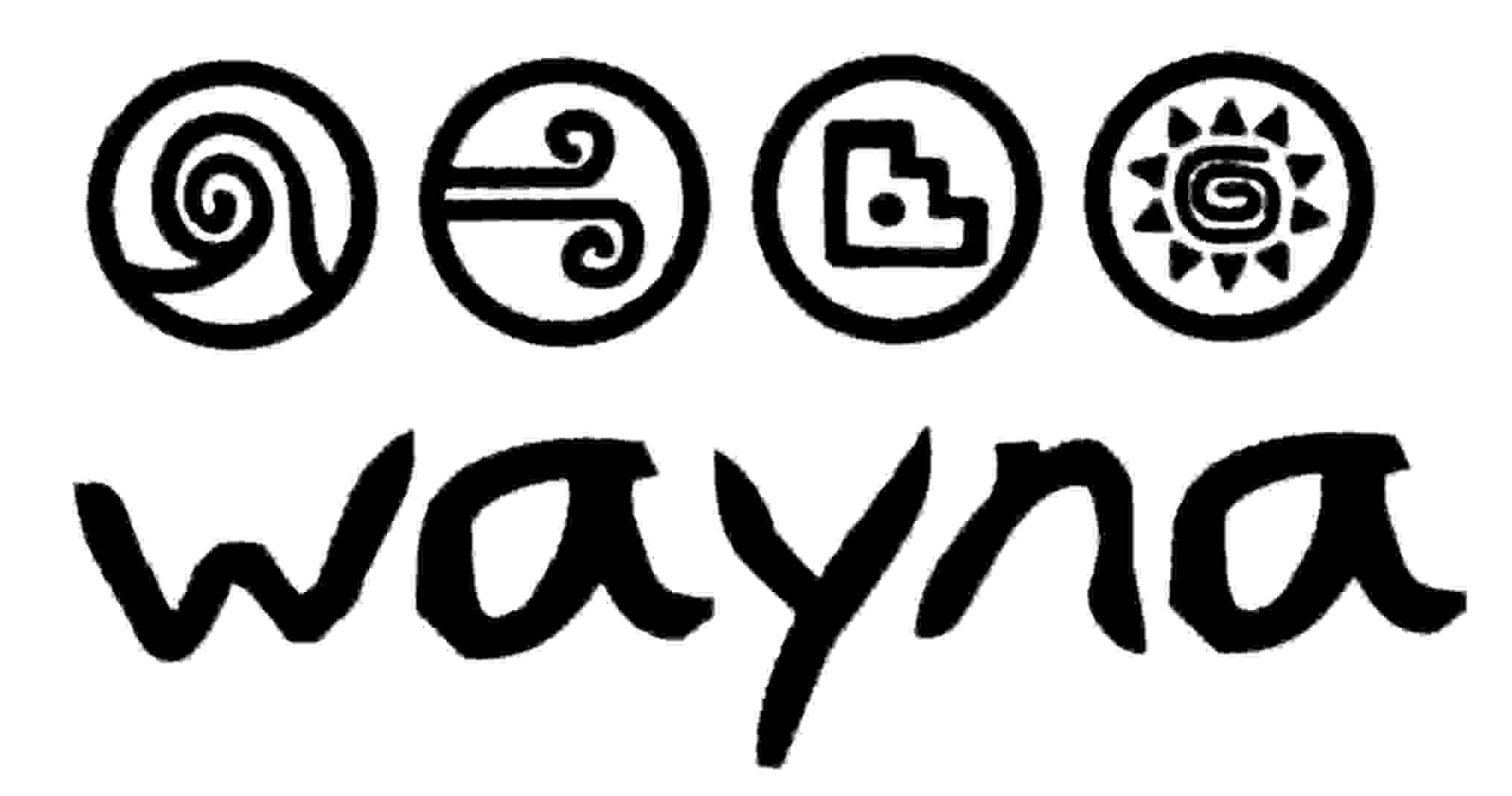

La integración de los símbolos tradicionales andinos en la campaña de formación para la preservación de los recursos naturales, Wayna, dirigida a colegios estatales y privados, del Colectivo Gráfico. Creación: Andrea Maita.

Paralelamente, para el espacio ajeno, el interés de cada comunidad es ingresar $e$ interactuar con los
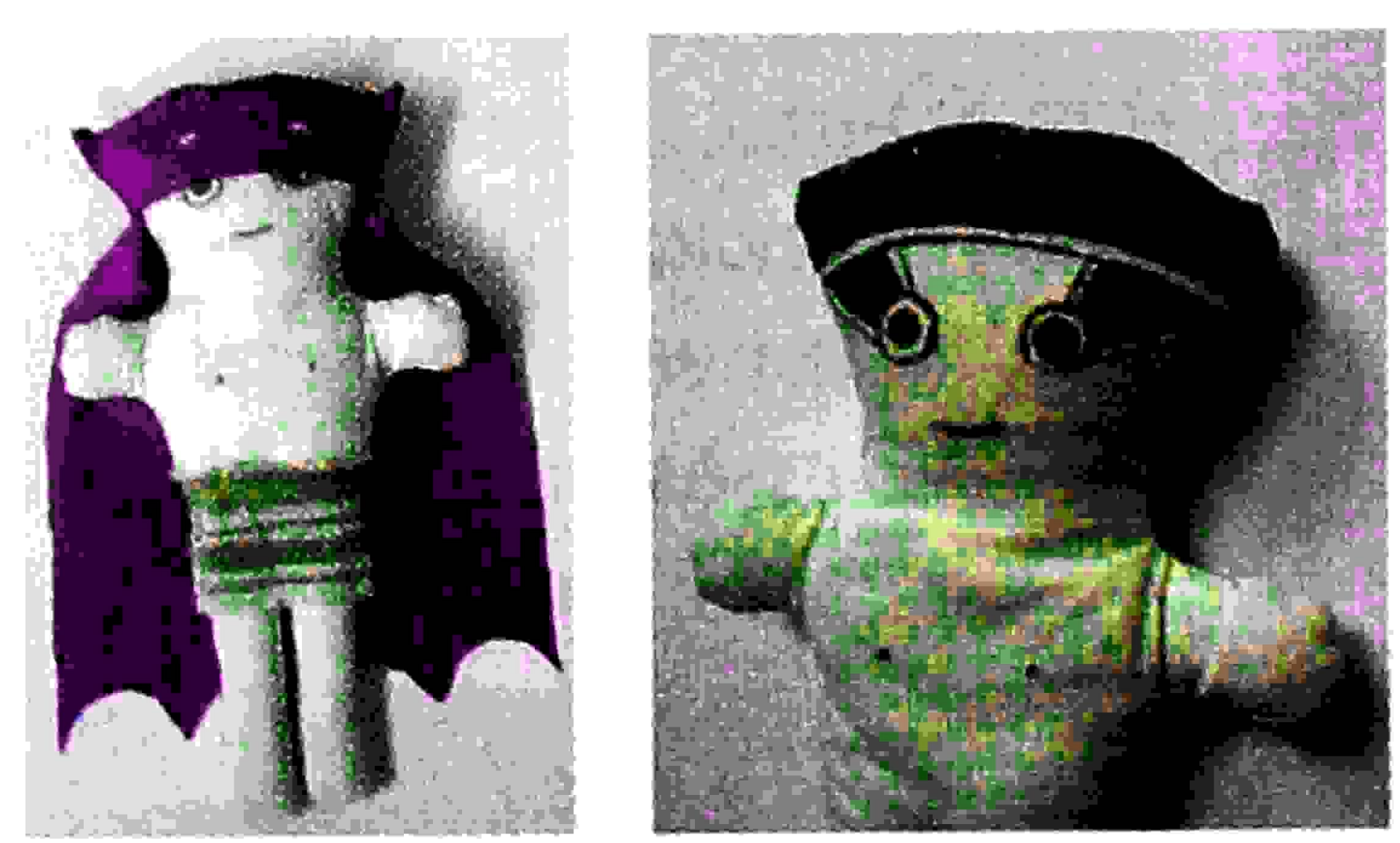

La integración de un personaje tradicional peruano, el Cuchimilco, al imaginario globalizado de los personajes / valores con simbolismo heroico, para la identificación de una marca de productos alimenticios andinos.

Creación : Romina Ruggero, del Colectivo Gráfico. signos que identifican los valores de su cultura.

Es una problemática que atañe a la economía y política cultural de toda comunidad, pero, en el caso de la cultura andina, requiere de una particular observación de la comunicación visual, como espacio donde se producen los primeros contactos y se inician los intercambios.

La observación debe ser seguida por la acción, y la acción requiere de planificación, proyectos y recursos.

Es en este campo que se inscriben los aportes de este artículo: la investigación y creación de un diseño que ingrese y funcione en la comunicación visual como agente activo del intercambio simbólico de valores, con acción inmediata en la propia cultura peruana y acción proyectada en la cultura mundial de la globalización.

Las dimensiones del Proyecto de Investigación y Creación Gráfica del cual se han seleccionado los 


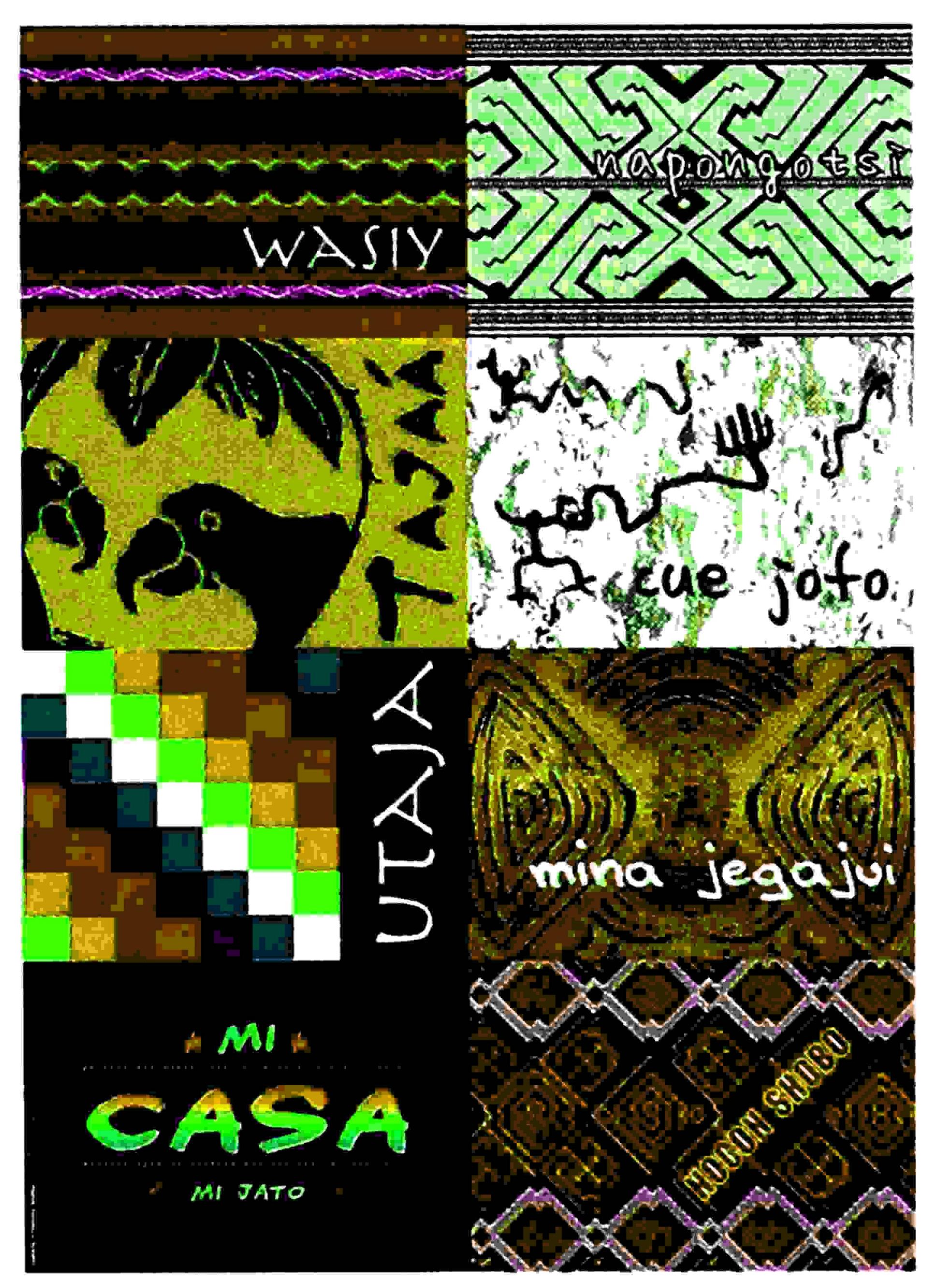

Afiches de la campaña VIP, voluntad de inclusion peruana, desde la diversidad a la integración e interacción cultural nacional e internacional. Creación: Pierre Jaramillo, del colectivo Absolutamente Perú.

ejemplos visuales de este artículo, son demasiado grandes para poder ser referidas aquí, pero sí es posible mostrar como funciona el diseño que propone, enfocando uno de sus recursos, cargado de significación y poder, con efecto directo y contundente en la realización de la intención comunicativa anteriormente expuesta. No obstante, es necesario indicar que se trata de un proyecto construi- do y realizado (aunque no finalizado) por el Equipo de Interés Absolutamente Gráfico de la Pontificia Universidad Católica del Perú, al cual pertenezco, junto con estudiantes, profesores y egresados de la Especialidad de Diseño Gráfico de la Facultad de Arte de la PUCP y de otras especialidades.

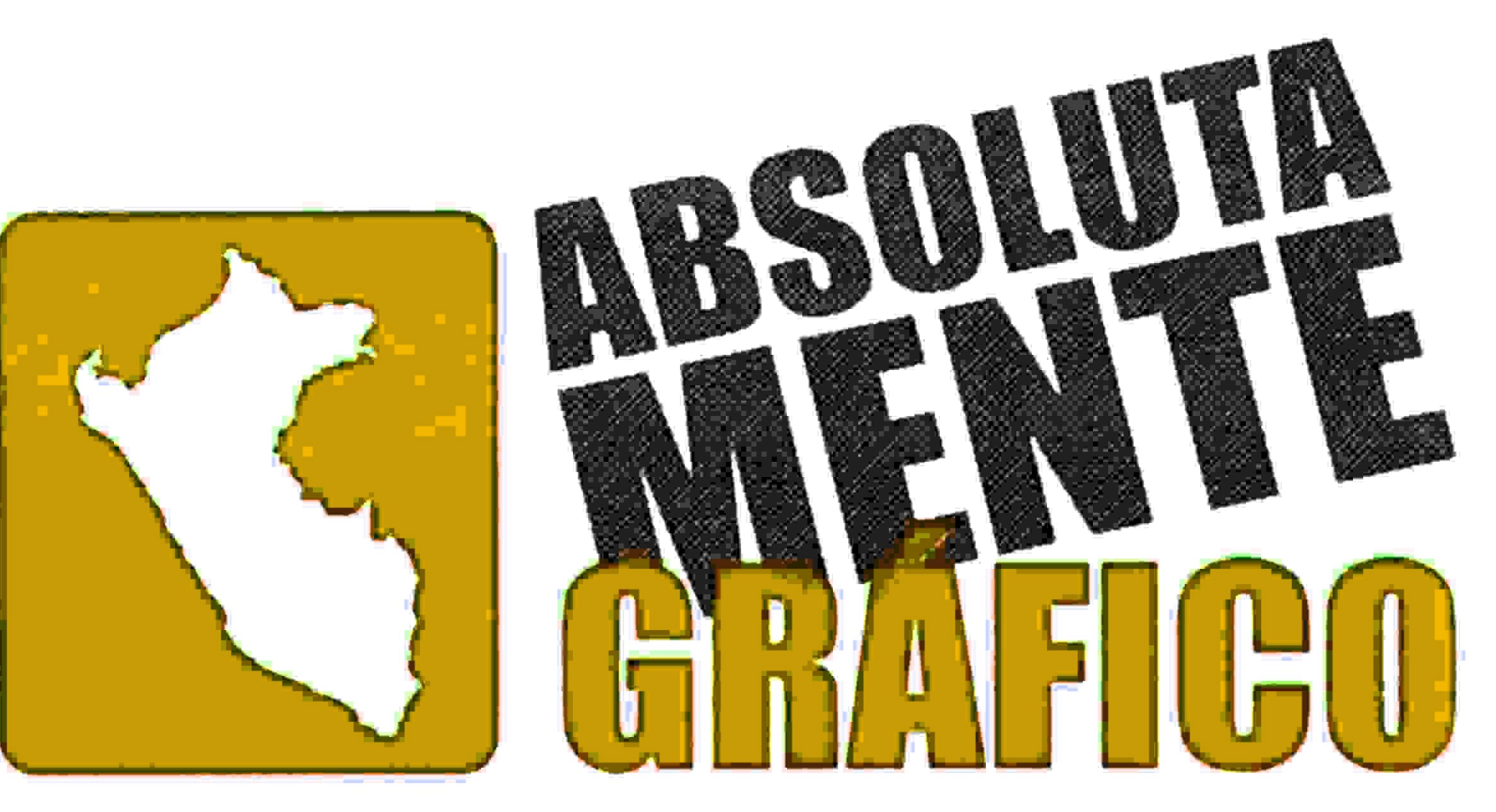

Logotipo del Equipo de Interés Absolutamente Gráfico

La cultura visual de los últimos años ha puesto en vitrina, entre los recursos de la globalización cultural, un recurso que desarrolla valores festivos y lúdicos, y que -a través de la interacción de las formas y contenidos- se centra en el valor simbólico de la hibridación: la intertextualidad.

¿En qué consiste? Formalmente hablando, la intertextualidad caracteriza a una imagen que remite a otra imagen u otras imágenes, 
porque lleva en su composición partes de éstas(s). El resultado es un discurso visual que se ha apropiado de elementos de otras imágenes/discursos visuales: signos, estructuras compositivas, estéticas. Lo ha hecho con un propósito: enriquecer la interpretación a través del estímulo de conexiones que se generan en la mente de cada observador, gracias a su vínculo con el imaginario colectivo.

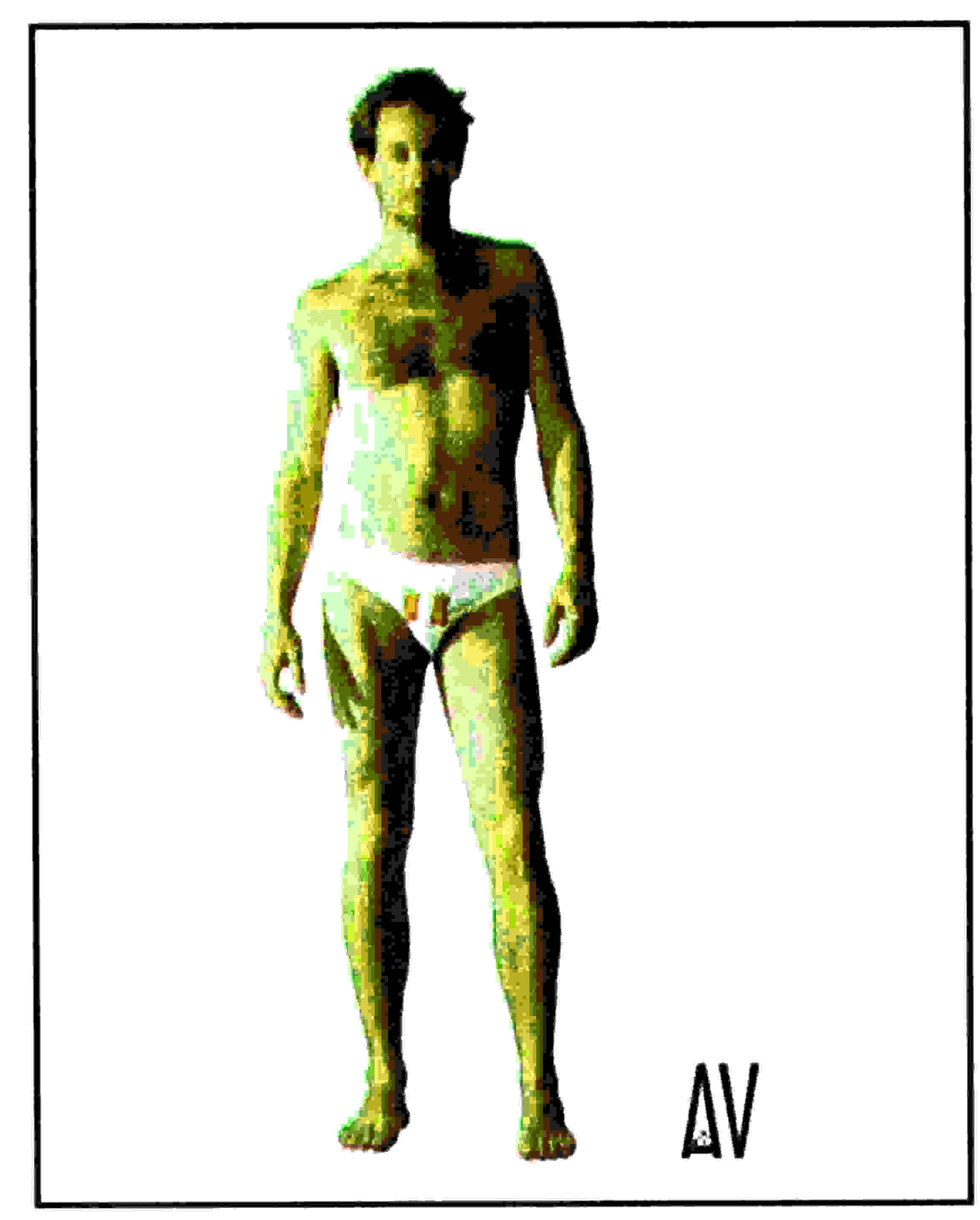

Personaje publicitario de la campaña de moda DGP: Absolutamente Vanguardista,realizada por el colectivo Absolutamente Perú, que provoca al observador a asociaciones y conclusiones propias. Creación: Edward Venero.
La actualización de la información perteneciente al imaginario colectivo permite que la nueva imagen tenga «historia», se aproveche de contenidos metales ya existentes. La creación del diseñador es reconocida por el observador más allá de la propia imagen. Esta conexión extendida aporta a la imagen intertextual vínculos y contenidos, a la vez que se proporciona al observador una participación activa en la construcción del sentido. Se consigue, de este modo, la extensión de la red de interacciones de la imagen receptora, acompañada de otros efectos: la ampliación del semantismo, a través de la integración de tiempos, espacios, identidades en la propuesta generada por un yo/aquí/ ahora; el estrechamiento de la originalidad $p E r$ se de la imagen, pero, al mismo tiempo, la reducción de su dependencia exclusiva del aquí / ahora, con lo cual funciona en una globalización de los espacios y de los tiempos.

Las interacciones ocurren entre: 1) la imagen y la mente del observador que activa su participación en el imaginario colectivo $y$, a través de éste, con la cultura visual; 2) entre los elementos internos que com- 


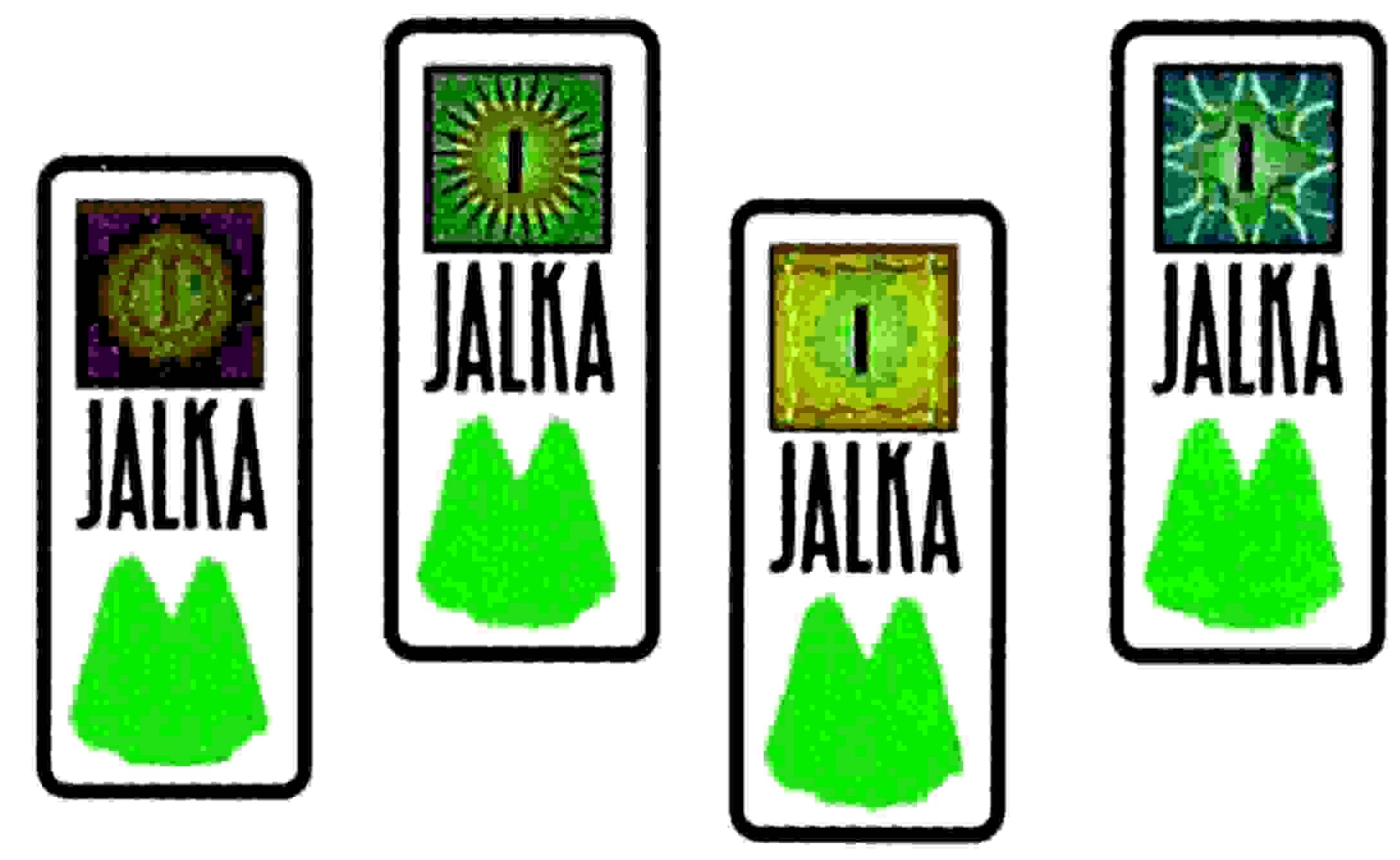

Etiquetas de ponchos, para la exportación La línea de moda Jalka hacen interactuar símbolos abstractos de los elementos naturales, de diferente origen. Creación Daniel Ochoa.

ponen la imagen. En el primer caso, se define la relación de interculturalidad, para definir la imagen como manifestación de una cultura híbrida. En el segundo caso, la interacción de los elementos, además de adentrarse en los sentidos de la hibridación de la imagen a través de un collage mental y físico, hace funcionar el intercambio simbólico de valores.

¿A partir de qué imágenes se construye la intertextualidad de la nueva imagen? Se retoman signos visuales que gozan de reconocimiento y prestigio, y que cuentan con una interpretación relativamente unívoca para construir, a partir de ellos, nuevos discursos.
Es, implícitamente, una demostración de la relatividad del paradigma, ya que permite la desconstrucción y la reconstrucción.

En el proceso, las fronteras de los sentidos se mueven, la identidad de lo otro queda intervenida y la nueva construcción de sentido incorpora los sentidos liberados en su propio diseño.
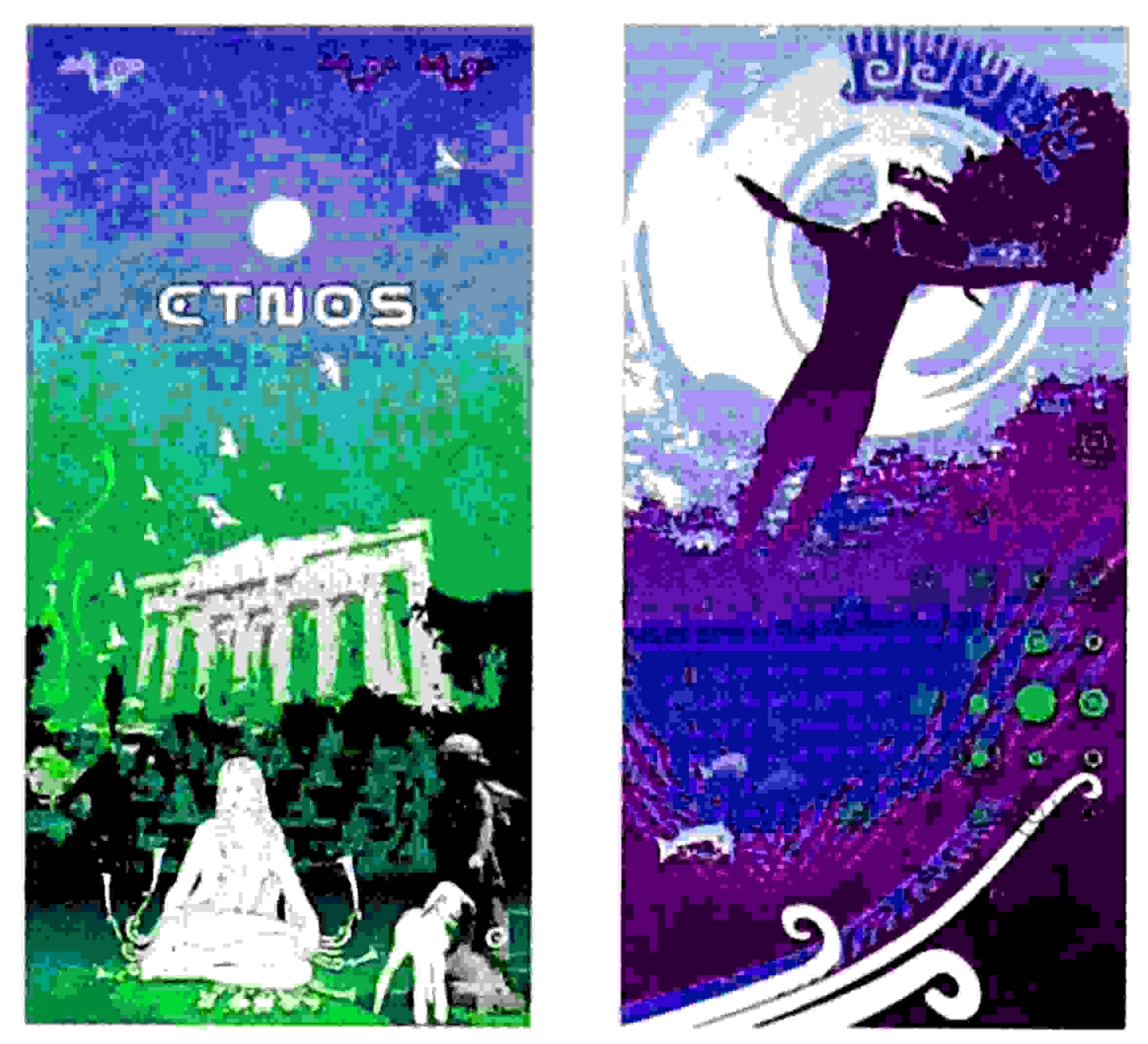

Artes para afiches publicitarios de la línea de moda Etnos, en los cuales interactúan elementos culturales de diferente origen, con fines de globalización. Creación: Cesar Condeso.

La apropiación de los valores del otro, sobre todo del otro legitimado como poder y situado jerárquicamente en un nivel superior, es a 
menudo abordada a través de una intertextualidad que festeja los sentidos (y los elementos visuales que los representa) de la comunidad desde la cual se procede a la apropiación. Las modalidades son propias del juego conceptual y formal.
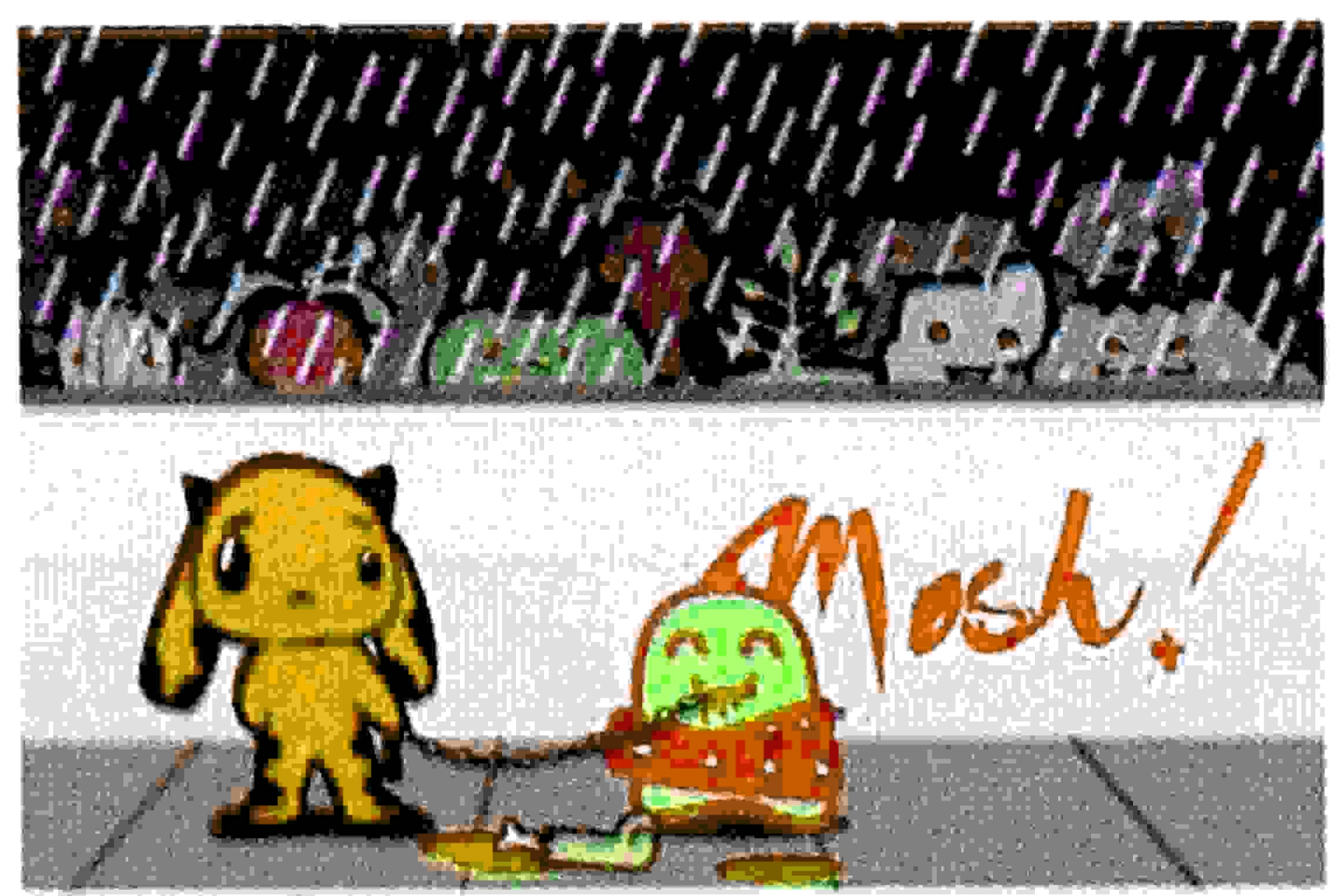

Personajes publicitarios para la línea de moda Mosh, en los cuales se realiza una intertextualidad entre la cultura japonesa y la cultura peruana. Creación: Leandra Cuba, Claudia Valenzuela, Melanie Cornejo

Concluyendo, podemos decir que:

- El interés del diseñador por la intertextualidad no se basa sólo en la necesidad de comprender su existencia y frecuencia en la cultura visual actual, de la cual saca sus parámetros y referentes, sino también en la posibilidad de ejercer un mayor control sobre las conclusiones que el observador construye a partir de la interpretación de la imagen : las conclusiones son importantes como procedimiento de lectura interpretativa de la imagen por parte del lector ( función referencial, a través de la cual se consigue la realización del mensaje de la imagen) y como fuentes generadoras de valores ( función contextual).

- A la vez, la intertextualidad sería una solución particular de la oposición entre la construcción cerrada del sentido y la construcción abierta, ofreciendo al observador la posibilidad de generar sentidos con relativa facilidad pero con un alto rango de implicación. Esto significa que el proyecto comunicativo plantea un mensaje de intercambio, horizontal, dialógico e integrador, donde la intertextualidad es un facilitador de la integración. El público se siente partícipe, o se siente a gusto ante la imagen / signo.

Es así como la intertextualidad pone en marcha valores utópicos, asociados a los valores lúdicos. 
Concluiremos estos parámetros conceptuales de la problemática abordada (cuya acción es ilustrada con ejemplos de diseño de «Absolutamente gráfico») resaltando el valor de la intertextualidad en la comunicación globalizada: con un extenso potencial referencial, la imagen se carga de contenidos que interactúan entre sí, para superar tensiones e incongruencias, a la vez que establece vínculos fuertes con la memoria y la lógica del observador, al cual llama e implica en su juego. La significación resultante es más que la suma de los senti- dos derivados de los contenidos puestos en contacto a través de la interacción de las formas; induce a la utopía o a la crítica, pasando por la reflexión en torno a la identidad singular y colectiva. Atractiva y exigente por el juego formal, la intertextualidad es también reflexiva y provocativa. Es más que un recurso, es un modo de pensar la creación, que se sumerge en la memoria colectiva para realizar una construcción discursiva, centrada en la visión del mundo de la comunidad, más que en un mensaje.

\section{Bibliografía:}

ECO, U.

1985 "Cultura de masas y 'niveles' de cultura», en Apocalípticos e integrados. Barcelona, Lumen.

MAINGUENEAU, D.

1987 Nouvelles Tendances en Analyse du Discours, París, Hachette.

VERÓN, ELISEO(A)

1987 «El sentido como producción discursiva», en La semiosis social, VERÓN, E. Barcelona, Gedisa.

1987 «Construir el acontecimiento», Buenos Aires, Gedisa. 

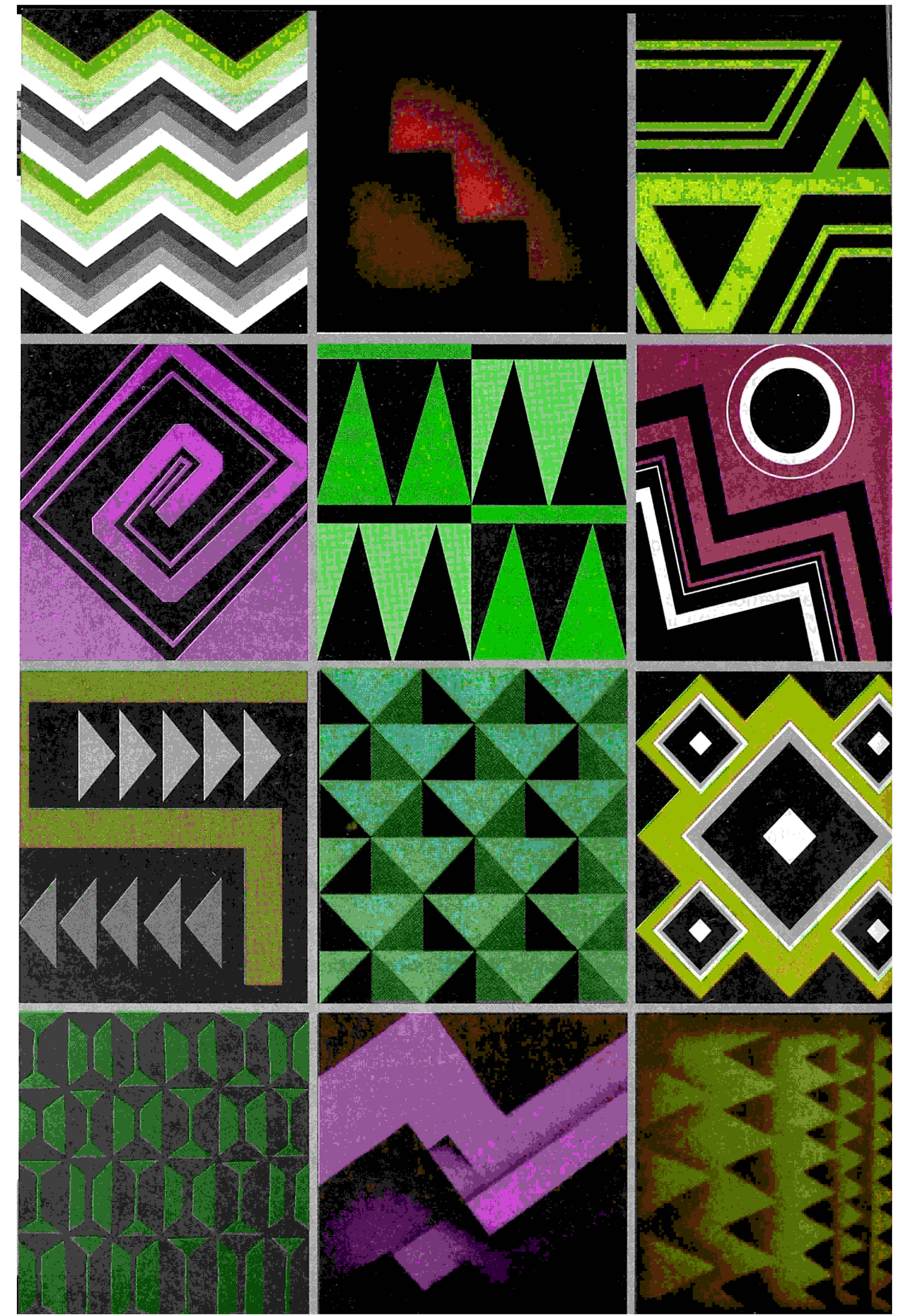